\section{POS0614 PERFUSE: A FRENCH PROSPECTIVE/ RETROSPECTIVE NONINTERVENTIONAL COHORT STUDY OF INFLIXIMAB-NAÏVE AND TRANSITIONED PATIENTS RECEIVING INFLIXIMAB BIOSIMILAR SB2; 12-MONTH ANALYSIS}

B. Fautrel ${ }^{1}$, Y. Bouhnik ${ }^{2}$, M. Dougados ${ }^{3}$, U. Freudensprung ${ }^{4}$, J. Addison ${ }^{5}$. ${ }^{1}$ Sorbonne University, Pitié-Salpêtrière Hospital, AP-HP, Paris, France; ${ }^{2}$ Beaujon Hospital, Paris Diderot University, Department of Gastroenterology, AP-HP, Clichy, France; ${ }^{3} \mathrm{CHU}$ Paris Centre - Hôpital Cochin, Service de Rhumatologie $B$, Paris, France; ${ }^{4}$ Biogen $\mathrm{GmbH}$, Medical Data Science and Analytics, Biosimilars, Baar, Switzerland; ${ }^{5}$ Biogen IDEC, Clinical Research, Biosimilars, Maidenhead, United Kingdom

Background: SB2 is approved in the EU as an infliximab (IFX) biosimilar, having demonstrated bioequivalence and similar efficacy, safety and immunogenicity as the reference. PERFUSE is an ongoing non-interventional study of 1233 patients (496 with rheumatology diagnoses, 737 with gastroenterology diagnoses) receiving SB2 as routine therapy.

Objectives: The aim of the study is to provide data on long-term outcomes in patients initiating SB2 in the real-world setting.

Methods: Adult patients eligible for inclusion in the rheumatology study cohorts have a diagnosis of Rheumatoid Arthritis (RA), Psoriatic Arthritis (PsA) or Axial Spondyloarthritis (axSpA) and had initiated SB2 in routine clinical practice after September 2017, either as their first IFX or transitioning from treatment with IFX reference or another IFX biosimilar. Outcome measures include SB2 dose, disease activity scores and persistence on SB2, over time and up to 24 months after initiation. This interim analysis is the first complete analysis of 12 month data on all rheumatology patients enrolled into the study at 9 specialist sites and followed up to the data extract date of 29th October 2020. The analysis provides an overview of baseline characteristics, disease scores, SB2 dose and persistence at 12 months post-initiation of SB2.

RESULTS:

Table 1. This 12-month interim analysis includes 496 patients (336 with axSpA, 98 with RA and 62 with PsA)

\begin{tabular}{|c|c|c|c|c|c|c|}
\hline & IFX na & $\begin{array}{l}\text { SpA cohort } \\
\text { ( } \mathrm{N}=336 \text {; } \\
\text { ive } 81 \text {, IFX-prior } \\
255)\end{array}$ & IFX & $\begin{array}{l}\text { RA cohort } \\
\quad(\mathrm{N}=98 \text {; } \\
\text { naïve } 22 \text {, IFX- } \\
\text { prior } 76)\end{array}$ & $\begin{array}{r}P \\
\text { IFX }\end{array}$ & $\begin{array}{l}\text { PsA cohort } \\
\text { ( } \mathrm{N}=62 \text {; } \\
\text { naïve } 14 \text {, IFX- } \\
\text { prior } 48 \text { ) }\end{array}$ \\
\hline \multicolumn{7}{|c|}{ Baseline characteristics } \\
\hline IFX-naïve & & $43.1(11.1)$ & & $53.1(15.9)$ & & $48.5(12.2)$ \\
\hline Transitioned from IFX & & 48.9 (12.4) & & $57.3(13.1)$ & & $53.1(13.0)$ \\
\hline \multicolumn{7}{|c|}{ Disease duration in years, mean (SD): } \\
\hline IFX-naïve & & $7.2(9.3)$ & & $11.3(9.8)$ & & $4.2(3.9)$ \\
\hline Transitioned from IFX & & $16.6(11.6)$ & & $17.3(8.8)$ & & $12.9(11.3)$ \\
\hline \multicolumn{7}{|l|}{ Women, n (\%): } \\
\hline IFX-naïve & & $26(32.1)$ & & $16(72.7)$ & & $6(42.9)$ \\
\hline Transitioned from IFX & & $79(31.0)$ & & $60(78.9)$ & & $15(31.3)$ \\
\hline \multicolumn{7}{|c|}{ SB2 Dose: $\mathrm{n}$, mean $\mathrm{mg} / \mathrm{kg}$ (SD) } \\
\hline \multicolumn{7}{|l|}{ IFX-naïve: } \\
\hline Baseline & 81 & $383.8(85.5)$ & 22 & $266.2(145.9)$ & 14 & 395.4 (108.9) \\
\hline Month 12 & 47 & $436.8(153.3)$ & 13 & $285.5(90.7)$ & 6 & $508.0(147.6)$ \\
\hline \multicolumn{7}{|l|}{ Transitioned from IFX: } \\
\hline Baseline & 255 & 396.7 (109.6) & 76 & $291.8(103.4)$ & 48 & 408.5 (91.3) \\
\hline Month 12 & 195 & 392.1 (105.5) & 60 & $287.8(106.6)$ & 41 & 421.4 (101.6) \\
\hline \multicolumn{7}{|c|}{ Disease score, mean (SD) } \\
\hline IFX-naïve: & $\mathrm{n}$ & BASDAI & $\mathbf{n}$ & DAS28 & $\mathbf{n}$ & DAS28 \\
\hline Baseline & 54 & $5.8(2.1)$ & 14 & $4.3(1.6)$ & $-^{\star}$ & $-^{\star}$ \\
\hline \multirow{2}{*}{\multicolumn{7}{|c|}{ Transitioned from IFX: }} \\
\hline & & & & & & \\
\hline Baseline & 206 & $3.0(2.0)$ & 62 & $2.6(1.2)$ & 20 & $2.2(1.2)$ \\
\hline Month 12 & 151 & $3.0(2.1)$ & 47 & $2.7(1.2)$ & 19 & $2.1(0.9)$ \\
\hline \multicolumn{7}{|c|}{ KM estimate of persistence on SB2 by Month 12; proportion, $(95 \% \mathrm{Cl})$} \\
\hline IFX-naïve & 56.2 & $(44.43 ; 66.51)$ & 59.09 & $9(36.10 ; 76.21)$ & 64.29 & $9(34.33 ; 83.31)$ \\
\hline Transitioned from IFX & 79.8 & $(74.37 ; 84.30)$ & 80.26 & $26(69.42 ; 87.60)$ & 85.0 & $4(71.11 ; 92.58)$ \\
\hline
\end{tabular}

*Blank as disease score data for both baseline and Month 12 were provided by a single patien who was IFX-naïve and had PsA; IFX = infliximab; axSpA = Axial Spondyloarthritis; RA = Rheumatoid Arthritis; PsA = Psoriatic Arthritis; BASDAI = Bath Ankylosing Spondylitis Disease Activity Index; DAS28 = Disease Activity Score 28; CI = confidence interval; SD = standard deviation; KM = Kaplan Meier.

Conclusion: This 12-month analysis indicates that patients with axSpA or RA can be successfully initiated on SB2 as the first infliximab therapy, and patients with axSpA, RA or PsA can be transitioned from originator or biosimilar IFX to SB2 without loss of disease control and with no dose penalty over 12 months post-transition. Over $56 \%$ of IFX- naïve patients and over $79 \%$ of patients transitioned from prior IFX remained on SB2 at 12 months post-initiation. With follow-up of patients ongoing to 24 months post-initiation of SB2, the study will continue to provide pertinent information about clinical outcomes of initiation on SB2 as first IFX or after transition from reference or IFX biosimilar to SB2.

Acknowledgements: Data management for the study was provided by Sanoïa E-health services, Digital CRO, Gémenos, France; funding was provided by Biogen International $\mathrm{GmbH}$.

Disclosure of Interests: Bruno Fautrel Speakers bureau: AbbVie, Biogen, Boehringer-Ingelheim, BMS, Celgene, Janssen, Lilly, Medac, MSD, NORDIC Pharma, Novartis, Pfizer, Roche, SOBI, UCB., Consultant of: AbbVie, Biogen, Boehringer-Ingelheim, BMS, Celgene, Janssen, Lilly, Medac, MSD, NORDIC Pharma, Novartis, Pfizer, Roche, SOBI, UCB., Grant/research support from: AbbVie, MSD, Pfizer., Yoram Bouhnik Speakers bureau: AbbVie, Biogaran, Biogen, Boehringer Ingelheim, CTMA, Ferring, Gilead, Hospira, ICON, Inception IBD, Janssen, Lilly, Mayoly Spindler, Merck, Merck Sharp \& Dohme, Norgine, Pfizer, Robarts Clinical Trials, Roche, Sanofi, Shire, Takeda, UCB, Vifor Pharma. Consultant of: AbbVie, Biogaran, Biogen, Boehringer Ingelheim, CTMA, Ferring Gilead, Hospira, ICON, Inception IBD, Janssen, Lilly, Mayoly Spindler, Merck, Merck Sharp \& Dohme, Norgine, Pfizer, Robarts Clinical Trials, Roche, Sanofi, Shire, Takeda, UCB, Vifor Pharma., Maxime Dougados Grant/research support from: Biogen, Ulrich Freudensprung Shareholder of: Biogen, Employee of: Biogen, Janet Addison Shareholder of: Biogen, Employee of: Biogen DOI: 10.1136/annrheumdis-2021-eular.1642

\section{POS0615 TOCILIZUMAB IS SAFE AND EFFECTIVE IN ELDERLY PATIENTS WITH RHEUMATOID ARTHRITIS}

C. Specker ${ }^{1}$, M. Aringer ${ }^{2}$, G. R. Burmester ${ }^{3}$, M. Peters ${ }^{4}$, M. W. Hofmann ${ }^{5}$, H. Kellner ${ }^{6}$, F. Moosig ${ }^{7}$, H. P. Tony ${ }^{8}$, G. Fliedner ${ }^{9} .{ }^{1}$ Clinic Essen-Mitte, Clinic of Rheumatology and Clinical Immunology, Essen, Germany; ${ }^{2}$ Dresden University of Technology, University Medical Centre Carl Gustav Carus, Dresden, Germany; ${ }^{3}$ Free University and Humboldt University Berlin, Department of Rheumatology and Clinical Immunology Charité - Universitätsmedizin Berlin, Berlin, Germany; ${ }^{4}$ Roche Pharma AG, Grenzach-Wyhlen, Germany; ${ }^{5}$ Chugai Pharma Germany GmbH, Rheumatology, Frankfurt am Main, Germany; ${ }^{6}$ Rheumatology and Gastroenterology Specialty Practice, Rheumatology, Munich, Germany; ${ }^{7}$ Rheumatology Centre Schleswig-Holstein Middle, Rheumatology, Neumünster, Germany; ${ }^{8}$ Medical Clinic II, Department of Rheumatology and Clinical Immunology, University Clinic Würzburg, Würzburg, Germany; ${ }^{9}$ Rheumatology Practice, Osnabrück, Germany

Background: Average life spans of patients with rheumatoid arthritis (RA) are approaching those of the general population. This results in a large proportion of RA patients being elderly at some point and underlines effective RA treatments needed for this population. Pivotal clinical trials have demonstrated the efficacy of tocilizumab (TCZ) for the treatment of RA. However, real-world studies that explore the effectiveness of TCZ especially in the elderly are lacking. ICHIBAN was a large, observational study that followed patients with RA treated with TCZ under real-world conditions in Germany for up to 2 years.

Objectives: In this analysis of ICHIBAN, we examined the safety and effectiveness of long-term TCZ treatment according to patient baseline $(B L)$ age $(<50$, $50-65,>65$ years).

Methods: ICHIBAN (NCT01194401) was a prospective, non-interventional study that observed adult patients with active moderate to severe RA in German rheumatology clinics and practices. Patients were treated with TCZ according to the local label. The safety analyses set (SAF) included all patients who received at least one dose of TCZ. The effectiveness set (EFF) included all patients from the SAF who had no prior TCZ therapy. Patient-reported outcomes (PROs) were assessed using the visual analogue scale. Last observation carried forward was used to substitute for missing values.

Results: At baseline (BL), 3,164 patients were included in the SAF: $29.2 \%<50$ years, $47.3 \% 50-65$ years, and $23.5 \%>65$ years old $(1.2 \% \geq 80$ years). Patients $>65$ years old were not only the most likely to have comorbidities such as hypertension, anaemia, renal insufficiency, osteoporosis, diabetes, and coronary heart disease, but also had the highest $\mathrm{BL}$ disease activity according to Disease Activity Score-28 erythrocyte sedimentation rate (DAS28-ESR) and Clinical Disease Activity Index (CDAI) (Table 1).

Proportions of patients with adverse events (AEs) considered related to treatment were similar in patients $<50(22.3 \%), 50-65(21.9 \%)$ and $>65$ years $(22.2 \%)$ More patients $>65$ years $(20.2 \%)$ and $50-65$ years $(14.4 \%)$ experienced serious AEs (SAEs) than patients $<50$ years $(11.5 \%)$. Slightly more patients $>65$ years old experienced infectious SAEs $(4.8 \%)$ than younger patients $(<50$ years, $3.2 \%$ and 50-65 years, 3.1\%). Yet, similar proportions of patients across all age groups discontinued TCZ due to AE $(7.0 \%<50$ years; $9.6 \% 50-65$ years; $7.8 \%>65$ years). 2,902 patients were included in the EFF. Patients $<50$ years experienced DAS28ESR remission at least once during the treatment period $(65.4 \%)$ more often than patients aged $50-65$ years $(59.8 \%)$ or $>65$ years $(59.5 \%)$. However, patients $>65$ years had numerically greater improvements in DAS28-ESR (Table 1). Patients $<50$ years had the best physical functioning at $\mathrm{BL}$ and the greatest reduction in 
Health Assessment Questionnaire Disease Index (HAQ-DI) score (Figure 1A). All age groups had similar improvements in PROs such as fatigue, strength of pain, and sleep disturbances (Figure 1B).

Table 1. Mean Disease Activity Score-28 erythrocyte sedimentation rate (DAS28-ESR) and Clinical Disease Activity Index (CDAI) over the course of ICHIBAN. BL, baseline; SD, standard deviation.

\begin{tabular}{lcccc}
\hline & & $<50$ years & $\mathbf{5 0 - 6 5}$ years & $>\mathbf{6 5}$ years \\
\hline DAS28-ESR, mean $\pm \mathrm{SD}$ & $\mathrm{n}^{*}$ & 777 & 1237 & 617 \\
& $\mathrm{BL}$ & $4.9 \pm 1.4$ & $5.3 \pm 1.3$ & $5.4 \pm 1.3$ \\
& Last visit & $2.8 \pm 1.7$ & $3.1 \pm 1.7$ & $3.2 \pm 1.7$ \\
& Change from BL & $-2.0 \pm 1.7$ & $-2.2 \pm 1.7$ & $-2.2 \pm 1.8$ \\
& $\mathrm{n}^{*}$ & 768 & 1217 & 590 \\
& $\mathrm{BL}$ & $25.7 \pm 12.8$ & $28.4 \pm 13.3$ & $28.8 \pm 12.8$ \\
& Last visit mean $\pm \mathrm{SD}$ & $13.3 \pm 12.8$ & $14.6 \pm 13.2$ & $14.5 \pm 12.8$ \\
& Change from BL & $-12.5 \pm 13.6$ & $-13.8 \pm 14.0$ & $-14.3 \pm 13.8$ \\
\hline
\end{tabular}

*271 patients with missing data at $\mathrm{BL}^{\star *} 327$ patients with missing data at $\mathrm{BL}$

Conclusion: Although elderly patients experienced a higher rate of infections, the proportion of patients withdrawing due to $A E$ was not higher than in the other age groups. Starting with higher baseline disease activity, patients $>65$ years had similar benefits to disease activity and PROs when compared with younger patients. Overall, these results indicate that long-term TCZ treatment of elderly patients is effective and has an acceptable safety profile.

Figure. Mean (SD) Health Assessment Questionnaire Disease Index (HAQ-DI) score and B) mean (SD) patient-reported outcomes over the course of ICHIBAN. SD, standard deviation.

A

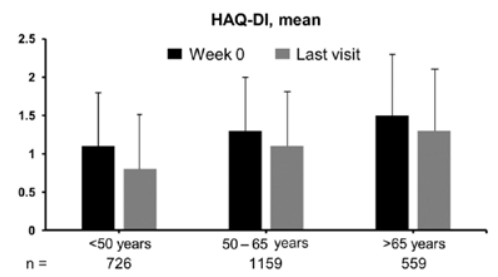

B

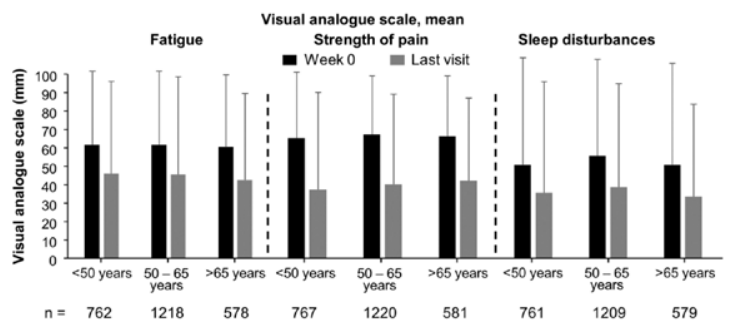

Disclosure of Interests: Christof Specker Speakers bureau: AbbVie, Celgene, Chugai, Janssen-Cilag, Lilly, MSD, Novartis, Pfizer, Roche, and UCB, Consultant of: AbbVie, Boehringer Ingelheim, Chugai, Lilly, Novartis, Sobi, and UCB, Grant/ research support from: Boehringer, Chugai, GSK, and Roche, Martin Aringer Speakers bureau: Roche and Chugai, Consultant of: Roche and Chugai, Grant/ research support from: Roche, Gerd Rüdiger Burmester Consultant of: Lilly, Pfizer, Sanofi, and Roche, Grant/research support from: Roche, Marvin Peters Employee of: Roche Pharma AG, Michael W. Hofmann Employee of: Chugai Pharma Germany GmbH, Herbert Kellner Consultant of: Roche, Grant/research support from: Roche, Frank Moosig Grant/research support from: Roche, Hans-Peter Tony Speakers bureau: Roche, Abbvie, BMS, Chugai, Janssen, Novartis, Sanofi, and Lilly, Consultant of: Roche, Abbvie, BMS, Chugai, Janssen, Novartis, Sanofi, and Lilly, Grant/research support from: Roche, Gerhard Fliedner Grant/research support from: Roche, Chugai, Abbvie, and Lilly

DOI: 10.1136/annrheumdis-2021-eular.1711

\section{POS0616 LONG-TERM EFFECTIVENESS AFTER MULTIPLE CYCLES WITH RITUXIMAB FOLLOWING AN ON-FLARE RETREATMENT STRATEGY IN PATIENTS WITH RHEUMATOID ARTHRITIS}

D. Bertrand ${ }^{1}$, N. Pype ${ }^{1}$, T. Conings ${ }^{1}$, D. De Cock ${ }^{1}$, S. Pazmino ${ }^{1}$, M. Doumen ${ }^{1,2}$, J. Joly ${ }^{2}$, B. Neerinckx ${ }^{1,2}$, R. Westhovens ${ }^{1,2}$, P. Verschueren ${ }^{1,2} .{ }^{1} K U$ Leuven, Skeletal Biology and Engineering Research Center, Leuven, Belgium; ${ }^{2} U Z$ Leuven, Rheumatology, Leuven, Belgium

Background: Rituximab is known as an efficacious drug for the treatment of Rheumatoid Arthritis (RA). The recommended administration schedule consist of 2 infusions of $1000 \mathrm{mg}$ with a 2 -week interval. In Belgium an on-flare retreatment strategy is followed, making evaluation of effectiveness over time challenging. Moreover the patient's view on this strategy is unclear.

Objectives: To explore long-term effectiveness and safety of rituximab in daily clinical practice in patients with RA.

Methods: Data of patients diagnosed with RA and treated with rituximab in a tertiary university hospital were retrospectively collected. For every cycle, clinical data were recorded at the time of the first and second infusion, the 16-week visit and the visit on which the treating rheumatologist decided to prescribe a new cycle. Data on demographics, previous RA treatment, disease activity, patient-reported outcomes, adverse events related to rituximab, dose and number of cycles were collected from 01/01/2006 until 01/12/2019 or until discontinuation of rituximab. The visit on which rituximab was prescribed for the first time was considered as the baseline visit. The data were analysed descriptively.

Results: Data of 66 patients with RA were collected. The median (IQR) age was 57.0 (47.0-65.0) years at baseline and 56\% (37/66) were female. Most patients were seropositive (RF $91 \%$ and ACPA $92 \%$ ), and had erosive $(71 \%)$ or nodular disease (53\%). The median (IQR) disease duration was 12.5 (4.0-18.3) years. In total, $94 \%$ of the patients had failed at least one other biological Disease-modifying Antirheumatic Drug (bDMARD) before starting rituximab. Overall, patients received a median (IQR) of 3 (2-7) cycles of rituximab. Seven of the 66 patients $(11 \%)$ discontinued rituximab and changed to another bDMARD after a median (IQR) of 1 (1-6) cycles and $11 \%$ were treated with a lower dose than $2 \times 1000 \mathrm{mg}$ The median (IQR) interval between the first 2 cycles was 7.0 (6.0-10.0) months after which this increased to up to one year (interval between cycle 2-3: 10.0 (7.0-13.0) months, cycle 3-4: 12.0 (7.3-15.5) months). The overall median (IQR) follow-up time was 45.5 (14.8-82.3) months. The efficacy of rituximab remained after repeated cycles: after every treatment with rituximab, a reduction in disease activity based on the disease activity score in 28 joints (DAS28) could be noticed (figure $1 \mathrm{~A})$. The evolution in patients' $(\mathrm{PaGH})$ and physicians' global health $(\mathrm{PhGH})$ assessment followed the same pattern as the DAS28-score (Figure 1B). High PaGH-scores could be noticed at every start of a new rituximab cycle. The proportion of patients with a PaGH-score above 20 ranged from $84 \%-100 \%$, $74 \%-100 \%$ and $66 \%-86 \%$ at the first infusion, second infusion and week 16 visits, respectively. Rituximab was considered to be well-tolerated. In total, 23 adverse events in 12 patients were recorded and none of them were serious. Conclusion: Rituximab can be considered a highly efficacious drug for RA treatment in daily practice. There were no major side effects and there was an increasing treatment interval over time. However, a healthy survivor effect should be kept in mind when interpreting the results. It should be noted that with the on-flare retreatment strategy, every new rituximab cycle was preceded by a rise in $\mathrm{PaGH}$-scores, which reflects a state of impaired wellbeing reported by patients. This should be further studied with qualitative methods and in a randomized trial setting comparing on-flare with fixed-interval retreatment to evaluate optimal effectiveness.

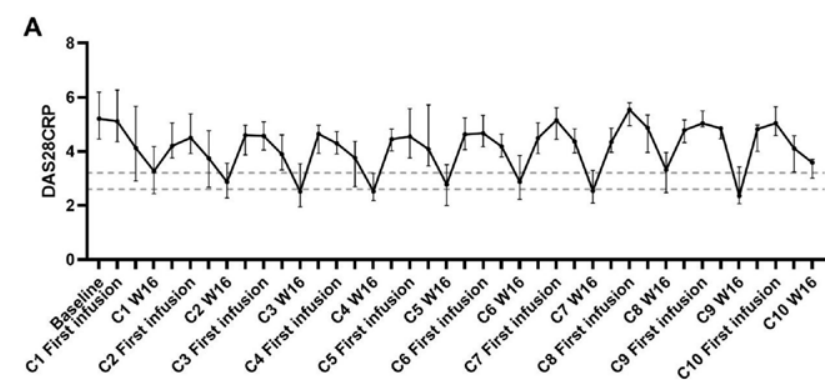

B

PaGH

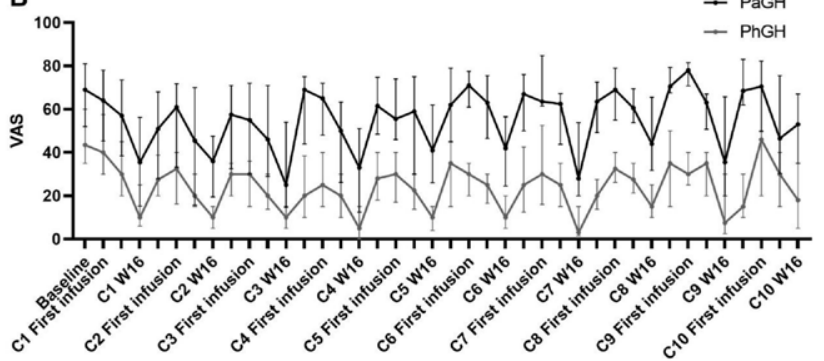

\begin{tabular}{c|cccccccccc} 
Cycle & 1 & 2 & 3 & 4 & 5 & 6 & 7 & 8 & 9 & 10 \\
\hline $\begin{array}{c}\text { Number of } \\
\text { patients }\end{array}$ & 66 & 54 & 42 & 32 & 28 & 26 & 17 & 13 & 11 & 7
\end{tabular}

Figure 1. Evolution in median - interquartile range disease activity (DAS28CRP) (A) and patients' $(\mathrm{PaGH})$ and physicians' global health $(\mathrm{PhGH})(\mathrm{B})$ over the different rituximab cycles. The disease activity, $\mathrm{PaGH}$ and $\mathrm{PhGH}$ were measured at baseline, the time of the first and 